\title{
Utility of Field Spectroradiometer Data in Chlorophyll-a Estimation
}

\author{
Sima Bagheri ${ }^{1, *}$, Machteld Rijkeboer ${ }^{2}$ and Anatoly Gitelson ${ }^{3}$ \\ ${ }^{I}$ Department of Civil and Environ Engineering, New Jersey Institute of Technology, Newark, NJ 07102, USA \\ ${ }^{2}$ Centre for Limnology, NIOO-KNAW Rijksstraatweg, 63631 AC Nieuwersluis, The Netherlands \\ ${ }^{3}$ CALMIT, School of Natural Resources, University of Nebraska Lincoln, 303 Hardin Hall, 3310 Holdrege, Lincoln, NE \\ 68583-0973, USA
}

\begin{abstract}
We present here results supporting the use of Medium Resolution Imaging Spectrometer (MERIS)-based Near Infrared-Red algorithms for estimating chlorophyll- $a$ (chl- $a$ ) concentration in complex coastal waters. The objective of the study was to test the potential of universal applicability of NIR-Red algorithms, calibrated with (a) radiometric measurements and in situ data from inland waters in Nebraska, (b) MERIS data, acquired over Azov Sea in Russia, and (c) data synthetically generated using a radiative transfer model, to estimate chl- $a$ concentration in the Hudson/Raritan Estuary of New York/New Jersey. We used a set of in situ reflectance and water samples collected in the Hudson/Raritan Estuary of New York/New Jersey for this validation. The NIR-Red algorithms produced consistently accurate estimates of chl- $a$ concentration, ranging from $3.9 \mathrm{mg} \mathrm{m}^{-3}$ to $26.3 \mathrm{mg} \mathrm{m}^{3}$, with the root mean square error (RMSE) below $2 \mathrm{mg} \mathrm{m}^{-3}$. The algorithms do not need re-parameterization and it presents a strong case for the use of NIR-Red algorithms for real-time quantitative monitoring of Hudson/Raritan Estuary, and potentially other inland and coastal waters.
\end{abstract}

Keywords: MERIS based NIR-red model, Chlorophyll-a, Radiative Transfer Model, Hydrolight, CDOM, Spectroradiometer.

\section{INTRODUCTION}

The estuarine and coastal waters are optically very complex due to the high concentrations of suspended sediments and colored dissolved organic matter (CDOM) not related to phytoplankton chl- $a$ [1] which complicates the estimation of chl- $a$ concentration (e.g., [2-6]). Several algorithms have been developed and shown to yield accurate estimates of chl- $a$ concentration in turbid productive estuarine and coastal waters when reflectances in the red and near infrared (NIR) regions were used (e.g., [2, 3, 6-16]). The parameters of most of these algorithms were obtained comparing remotely sensed data with in situ measured chl- $a$ concentration from a particular geographical location or seasonal regime. This often requires re-parameterization of the algorithms for different waters.

It was shown recently that the parameters of the NIR-Red algorithms set, based on the limited datasets from Chesapeake Bay (USA), Lake Kinneret (Israel), and Azov Sea (Russia), closely matched the parameters of the NIRRed algorithms, developed based on an extensive dataset collected using field spectrometers in several turbid productive lakes in Nebraska, USA [14, 16, 17]. In [18] was shown that the NIR-Red algorithms based on the limited dataset from the Azov Sea and the Taganrog Bay [14] and Nebraska lakes [16] gave accurate estimates of chl- $a$ concentration when applied to a large number of

\footnotetext{
*Address correspondence to this author at the Department of Civil and Environ Engineering, New Jersey Institute of Technology, Newark, NJ 07102, USA; Tel: (973)596-2470; Fax: (973)596-5790;
}

E-mail: bagheri@njit.edu synthetically generated reflectance spectra, leading to the development of advanced versions of the NIR-Red algorithms.

The objective of the study was to test the potential of universal applicability of NIR-Red algorithms, calibrated with (a) radiometric measurements and in situ data from inland waters in Nebraska, (b) MERIS data, acquired over Azov Sea in Russia, and (c) data, synthetically generated using a radiative transfer model, to estimate chl- $a$ concentration in the Hudson/Raritan Estuary of New York/New Jersey.

\section{STUDY AREA}

The study area is the Hudson/Raritan Estuary of New York/New Jersey (Fig. 1). This partially mixed drowned river estuary is relatively shallow $(<8 \mathrm{~m})$ [19] with major fresh water discharges from the Hudson, Raritan, Passaic and Hackensack Rivers. Over the last century the quality of the estuarine water has degraded in part due to eutrophication, which disrupts the pre-existing natural balance of the system, resulting in phytoplankton blooms of both increased frequency and intensity in response to the over-enrichment. Dense and accelerated phytoplankton blooms ultimately increase oxygen demand on the system leading to episodes of hypoxia. A field campaign was carried out in the estuary during August 1999 to obtain in-situ measurements of subsurface irradiance reflectance $\mathrm{R}(0-)$, together with in situ water samples, that were later analyzed in the laboratory for their inherent optical properties (IOP) and concentration of water quality parameters (WQP) [20]. The data were subsequently used in establishment of bio-optical model of 


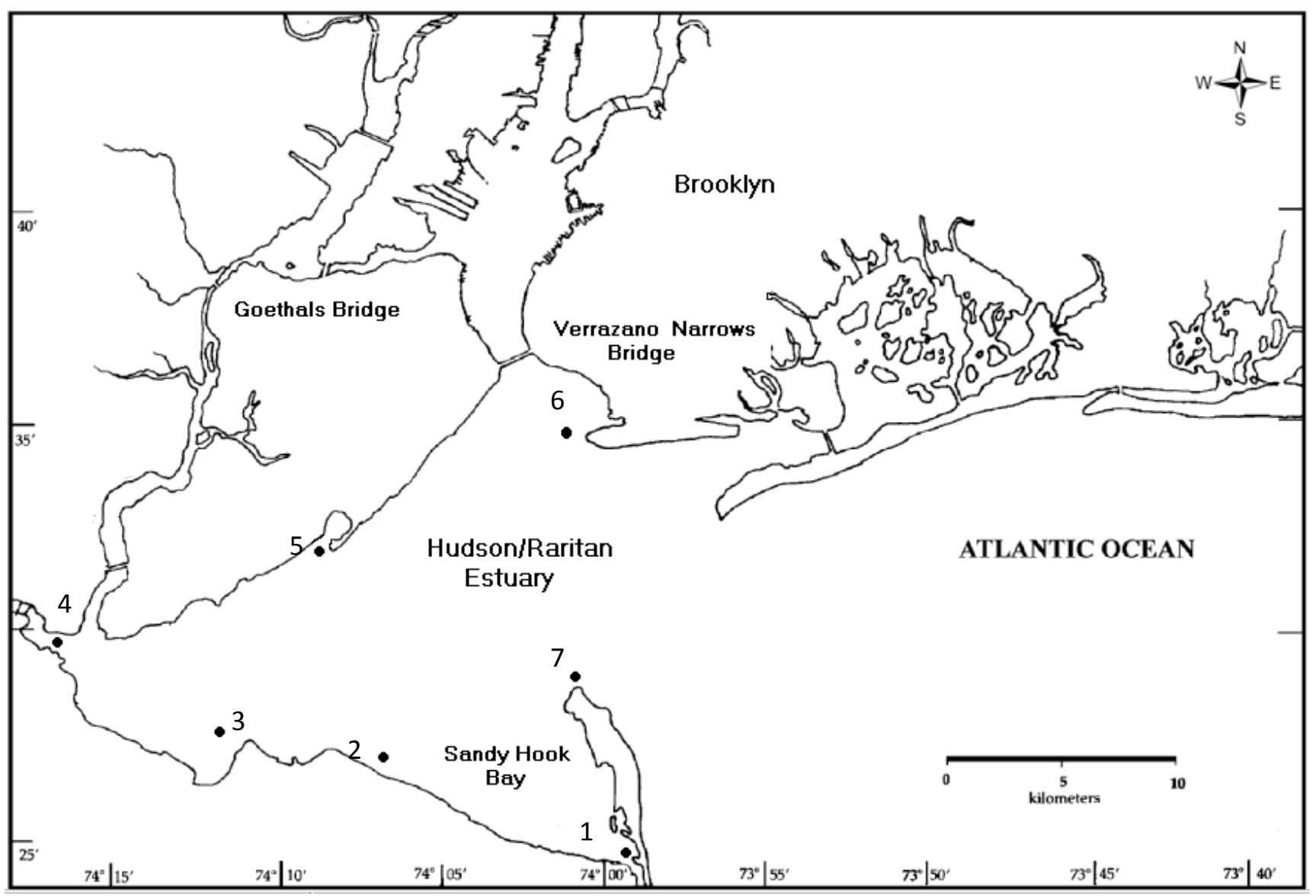

Fig. (1). Map of the study area with the locations of sample points.

the estuary and calibration of the Airborne Visible/Infrared Imaging Spectrometer (AVIRIS) data [21].

\section{RESEARCH MATERIAL AND METHODS}

\section{A. Spectral Reflectance Measurement}

Spectral reflectance for all stations marked on Fig. (1) was obtained using the field spectroradiometer. The goal was to establish the bio-optical model relating algal pigment concentrations and reflectance. The link between remotely sensed upwelling radiance and inherent optical properties (IOP) of water constituents is made through subsurface irradiance reflectance $\mathrm{R}(0-)$. The PR-650 portable telephotometer/colorimeter (Photo Research) was used for spectral radiance measurements above the water surface. This instrument included $1^{0}$ measuring optics and holographic grating, 128-element diode-array spectrometer that acquires spectra from 380 to $780 \mathrm{~nm}$ with full width at half maximum (FWHM) of $8 \mathrm{~nm}$. [3]. The water-leaving radiance $\left(\mathrm{L}_{\mathrm{au}}\right)$ and the downward radiance $\left(\mathrm{L}_{\text {sky }}\right)$ were measured at a nadir and a zenith angle of $42^{\circ}$, respectively. The angle of $42^{0}$ was used in order to avoid the influence from reflection and shading from the boat. The measured water-leaving radiance includes reflected sky light, which was subtracted using measured the sky radiance at the relevant angle. In order to calculate downward radiance $\left(\mathrm{E}_{\mathrm{ad}}\right)$ and discriminate between direct sunlight and the diffuse irradiance, the radiance was measured from a calibrated reflectance panel before $\left(\mathrm{L}_{\mathrm{rp}}\right)$ and after shading $\left(\mathrm{L}_{\mathrm{rpd}}\right)$. The direction of observation was $90^{\circ}$ to the plane of the sun. Each scan involved 10 measurement cycles of which the average was recorded. From the radiance measurements obtained above the water surface, the subsurface irradiance reflectance $\mathrm{R}(0-)$, i.e. the ratio of upward $\left(\mathrm{E}_{\mathrm{wu}}\right)$ and downward irradiance $\left(E_{w d}\right)$ just beneath the water surface was computed, as described in [3] and shown in Fig. (2).

\section{B. Optical Water Quality Constituent Concentrations Measurements}

Standard procedures as described by [22] were used to determine the concentrations of total chlorophyll (TCHL) (sum of chlorophyll- $a$ and phaeopigment) and total suspended matter (TSM). The TCHL concentration was determined according to the Dutch standard norm [23]. This method is based on the extraction of chl- $a$ pigments from the phytoplankton using hot ethanol $\left(80 \%\right.$ at $\left.75^{\circ} \mathrm{C}\right)$. The TCHL is then determined spectrophotometrically, using the extinction of the solvent at 665 and $750 \mathrm{~nm}$. The phaeopigment concentration is determined similarly after acidification of the sample. Additional chlorophyll measurements were performed using extraction in cold acetone [24].

The TSM concentrations were determined according to the Dutch standard norm [25], by filtering samples over 0.45 $\mu \mathrm{m}$ Whatman $\mathrm{GF} / \mathrm{F}$ filters and drying the filters at $80^{\circ} \mathrm{C}$. Ignition loss was determined by ashing the filters with TSM at $550^{\circ} \mathrm{C}$. The filters were flushed with $10 \mathrm{ml}$ tap water to 


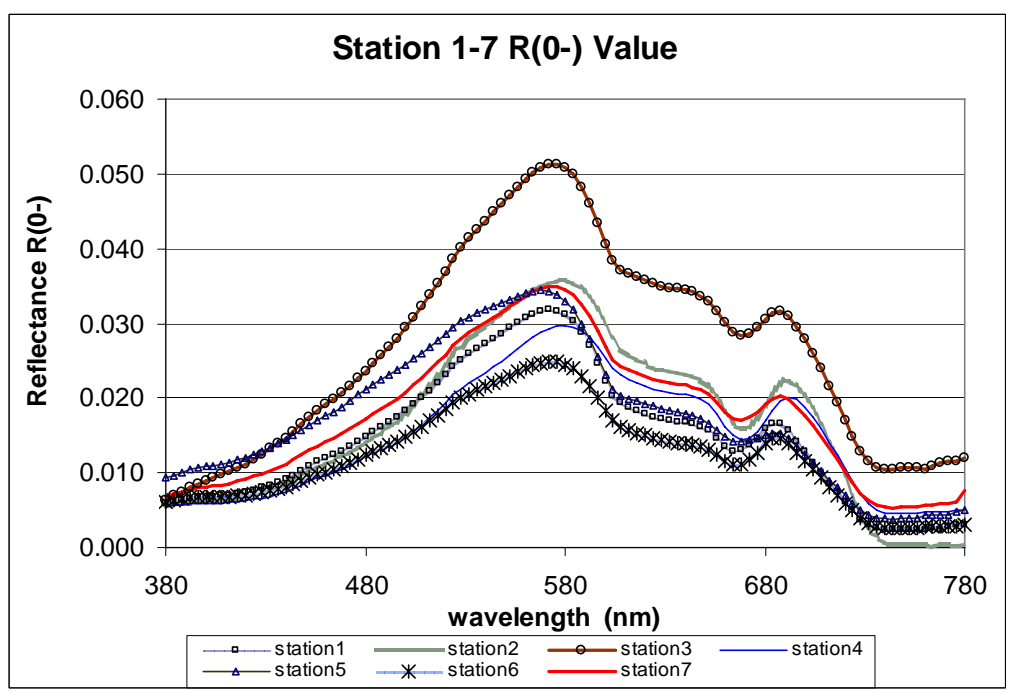

Fig. (2). Subsurface reflectance R(0-) measured by PR 650 for stations marked on Fig. (1).

Table 1. Reflectance Values in MERIS Bands

\begin{tabular}{|c|c|c|c|c|c|c|c|c|c|}
\hline $\begin{array}{c}\text { MERIS } \\
\text { Band }\end{array}$ & $\begin{array}{c}\text { Center } \\
(\mathbf{n m})\end{array}$ & $\begin{array}{c}\text { Bandwidth } \\
(\mathbf{n m})\end{array}$ & Station1 & Station 2 & Station 3 & Station 4 & Station 5 & Station 6 & Station 7 \\
\hline \hline 7 & 665 & 10 & 0.013 & 0.017 & 0.029 & 0.015 & 0.014 & 0.011 & 0.017 \\
\hline 9 & 705 & 10 & 0.010 & 0.016 & 0.024 & 0.016 & 0.010 & 0.009 & 0.015 \\
\hline 10 & 753 & 10 & 0.002 & 0.000 & 0.011 & 0.005 & 0.004 & 0.003 & 0.005 \\
\hline
\end{tabular}

prevent overestimation of the TSM concentration due to remaining salt left on the filter. The TSM ranges $(6.44-$ $25.74 \mathrm{~g} \mathrm{~m}^{3}$ ) are within the range expected and the TCHL concentrations were low $\left(6.33-47.79 \mathrm{mg} \mathrm{m}^{3}\right)$, since measurements did not coincide with any major outbreaks of phytoplankton blooms.

\section{Algorithms Tested}

NIR-Red algorithms, calibrated using extensive data taken in

Nebraska in 2008 [16], were:

Two-band model with MERIS spectral bands (2BM)

Chl- $a=25.28 \times(2 \mathrm{BM})^{2}+14.85 \times($ MERIS 2BM $)-15.18$

Three-band model with MERIS spectral bands (3BM)

Chl- $a=315.50 \times(\text { MERIS 3BM })^{2}+$

$215.95 \times($ MERIS 3BM $)+25.66$

where

$2 B M=\left[\left(R_{\text {band } 7}^{-1} \times R_{\text {band } 9}\right)\right]$

$3 B M=\left[\left\{\left(R_{\text {band } 7}^{-1}-R_{\text {band } 9}^{-1}\right) \times R_{\text {band } 10}\right\}\right]$

$R_{x}$ is the remote sensing reflectance in the $x$ MERIS spectral band.

NIR-Red algorithms, calibrated using MERIS data taken over the Azov Sea and Taganrog Bay [26], in the forms as follows:

Two-band MERIS NIR-Red algorithm:

Chl- $a=61.324\left[R_{665}^{-1} \times R_{708}\right]-37.94$
The three-band MERIS NIR-red algorithm:

$C h l-a=232.29\left[\left(R_{665}^{-1}-R_{708}^{-1}\right) \times R_{753}\right]+23.174$

where $R_{x}$ is the remote sensing reflectance in the spectral band centered at $x \mathrm{~nm}$.

Using comprehensive synthetic datasets of reflectance spectra, generated synthetically by the radiative transfer model, Hydrolight [27-29, 18], and inherent optical properties (IOP), related to a wide range of water parameters, as well as a new field data set, the two-band and three-band NIR-Red models were reformulated in terms of the absorption and scattering coefficients of the constituents water, phytoplankton, non-algal particles, and color dissolved organic matter (CDOM). Determining specific phytoplankton absorption coefficient $\left(a_{p h}^{*}\right)$ from a large set of synthetic and field data, advanced versions of the twoband and three-band NIR-Red algorithms were formulated as follows [18]:

Advanced two-band MERIS NIR-red algorithm:

Chl- $a=[35.75 \times 2 B M-19.3]^{1.124}$

Advanced three-band MERIS NIR-red algorithm:

Chl- $a=[113.36 \times 3 \text { BM-16.45 }]^{1.124}$

\section{RESULTS AND DISCUSSION}

Firstly, the NIR-Red models with MERIS spectral bands 7, 9 and 10 were calculated (Table 1) using Eqs. 3 and 4 with reflectances as measured in Hudson/Raritan Estuary. These model values were plotted versus actually measured chl- $a$ concentrations and presented in Fig. (3). The relationships were very close for both models with determination 

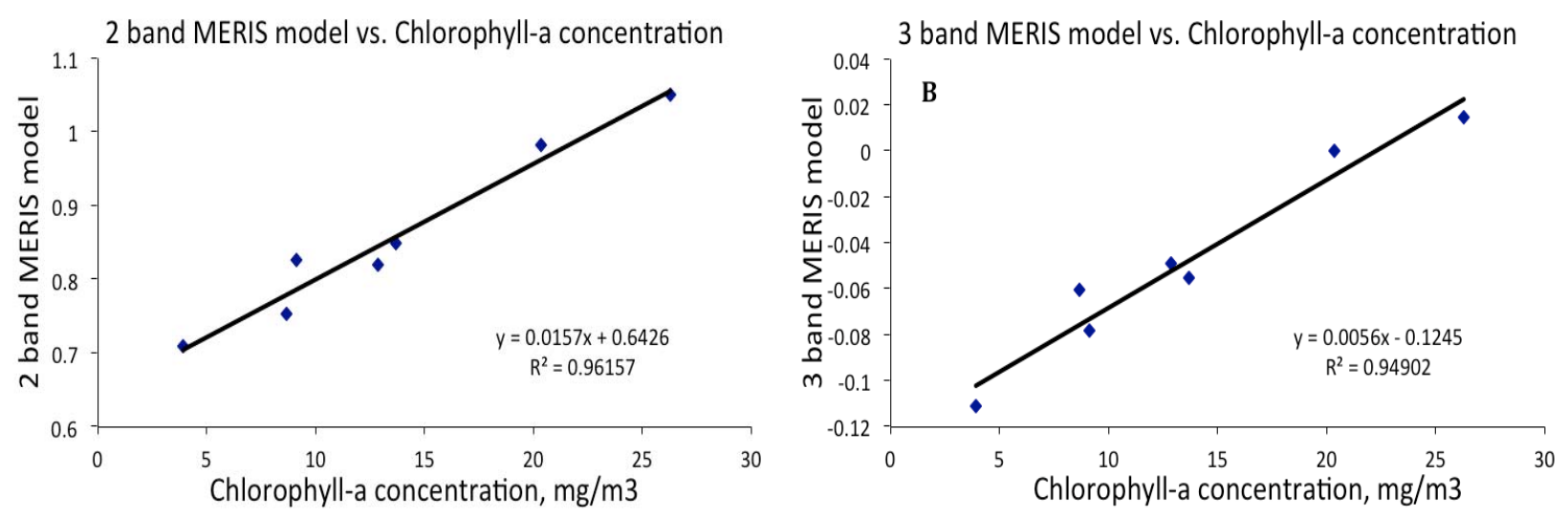

Fig. (3). Two- (A) and three-band (B) models with MERIS spectral bands calculated using measured reflectances plotted versus analytically determined chlorophyll-a concentrations in the Hudson/Raritan Estuary.

Table 2. Mean Bias, Mean Average Error, Root Mean Square Error of chl-a

\begin{tabular}{|c|c|c|c|c|}
\hline Algorithm & MB & MAE & RMSE & Author \\
\hline & $\mathrm{mg} \mathrm{m}^{-3}$ & $\mathrm{mg} \mathrm{m}^{-3}$ & $\mathrm{mg} \mathrm{m}^{-3}$ & \\
\hline 2 band $\mathrm{NE}$ & 2.76 & 2.76 & 3.08 & Gurlin et al., 2011 \\
\hline 3 band NE & 2.82 & 2.82 & 3.46 & Gurlin et al., 2011 \\
\hline 2 band MERIS & 0.90 & 1.20 & 1.70 & Moses et al., 2009 \\
\hline 3 band MERIS & -1.70 & 2.70 & 3.40 & Moses et al., 2009 \\
\hline 2 band advanced & 1.78 & 1.83 & 2.37 & Gilerson et al., 2010 \\
\hline 3 band advanced & 1.31 & 1.47 & 1.99 & Gilerson et al., 2010 \\
\hline
\end{tabular}

coefficient above 0.94. Two-band model performed slightly better than three band model in chl- $a$ estimation.

In second step, we predicted chl-a concentration ( $\left.\mathrm{Chl}_{\text {pred }}\right)$ in the Hudson/Raritan Estuary using algorithms established and calibrated based on the data, taken over Nebraska lakes (Eqs. 1 and 2). These predicted chl- $a$ concentration were compared to chl- $a$ concentrations measured ( $\left.\mathrm{Chl}_{\text {meas }}\right)$ analytically in Hudson/Raritan Estuary . Both models estimated the chl- $a$ concentrations accurately as shown in Table 2. The 2-band model had the lowest mean average error (MAE) and root mean square error (RMSE) (Table 2).

In third step we calculated the predicted chl- $a$ concentration $\left(\mathrm{Chl}_{\text {pred }}\right)$ in the Hudson/Raritan Estuary using algorithms established and calibrated based on MERIS data taken over Azov Sea (Eqs. 5 and 6). Chl pred was closely related and matched with $\mathrm{Chl}_{\text {meas }}$, which was analytically determined in the Hudson/Raritan Estuary. Both algorithms predicted chl- $a$ concentrations remarkably accurate (Table 2) and, as it was the case with the inland lakes in Nebraska (NE) calibrated algorithms, two-band algorithm performed better than three-band algorithm.

Finally, we calculated chl- $a$ concentration in the Hudson/Raritan Estuary using advanced models (Eqs. 7 and 8) and compared it with analytically measured chl- $a$ in the Hudson/Raritan Estuary (Fig. 4 and Table 2). Both models performed very accurately. It is significant, that best fit functions between predicted and measured chl-a concentration (dashed lines) for both models were very close to 1 by 1 line (solid line) indicating that $\mathrm{Chl}_{\text {pred }}=\mathrm{Chl}_{\text {meas }}$. It is also important to note that these advanced models, based on inherent optical properties of water constituents and water absorption, do not require any additional knowledge about inherent optical properties of water constituents.

Table 2 depicts the results of statistical analysis including mean normalized bias (MNB), mean average error (MAE), root mean square error (RMSE) of chl- $a$ estimation in the Hudson/Raritan Estuary using MERIS bands with different NIR-Red algorithms.

The 2- and 3-band NE algorithms (Eqs. 1 and 2) were established and calibrated in Nebraska on the basis of in situ reflectance measurements just below the water surface. The 2- and 3-band MERIS algorithms (Eqs. 5 and 6) were calibrated using MERIS data over Azov Sea. The advanced 2- and 3-band models (Eqs. 7 and 8) were developed in [18] are based on analyses of synthetic data sets and reflectance measurements. This remarkable consistency of the NIR-Red algorithms, which were calibrated in different geographic areas (Nebraska, USA and Azov Sea, Russia), as well as different data used with a wide range of chl- $a$ concentrations (synthetic data sets generated by the radiative transfer model Hydrolight [27], field measured reflectance in Nebraska, and MERIS satellite data taken over Azov Sea), demonstrates potential of NIR-Red models as tools for near real-time quantitative monitoring of chl- $a$ concentration in the Hudson/Raritan Estuary. It should be noted that advanced models (Eqs. 7 and 8) were also remarkably accurate in predicting chl-a concentrations.

Although a dataset with just seven stations is too limited to permit a comprehensive conclusion, but the excellent performance of the NIR-Red models demonstrate the applicability of MERIS-based NIR-Red models for reliable and accurate estimation of chl- $a$ concentration in turbid 

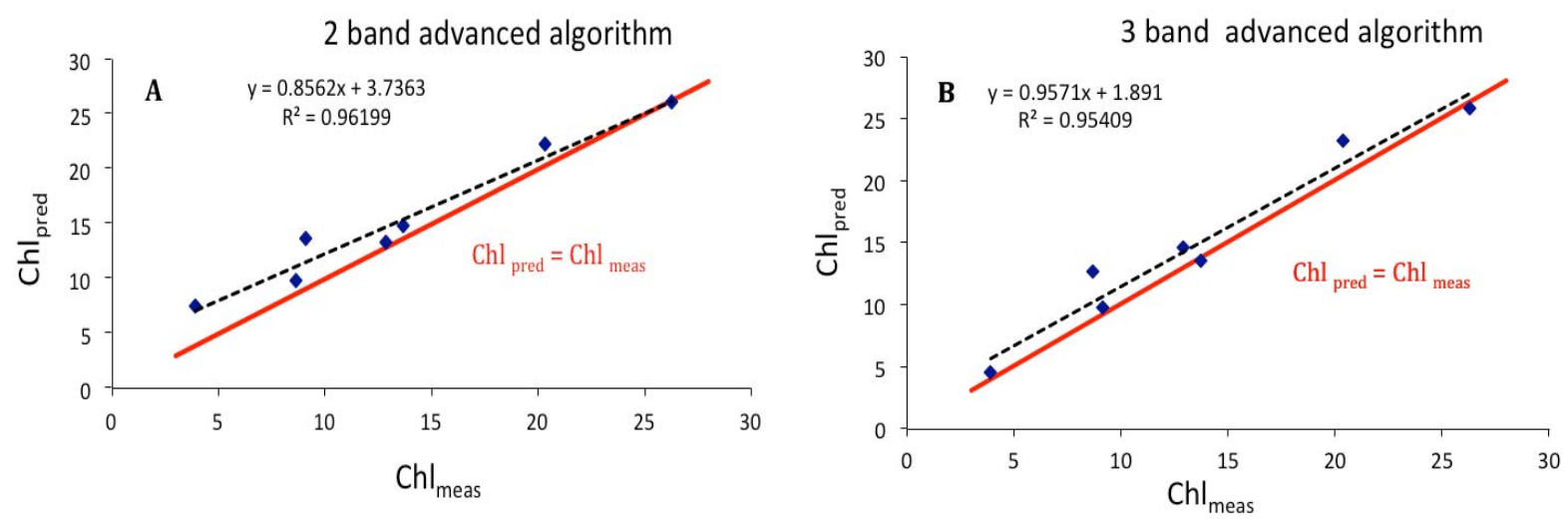

Fig. (4). Chlorophyll-a concentrations predicted by advanced two- (A) and three-band (B) models [18] - Equations 7 and 8, plotted versus analytically determined chlorophyll-a concentrations in the Hudson/Raritan Estuary. Dashed lines are best-fit functions, solid lines are 1 by 1 lines corresponding to $\mathrm{Chl}_{\text {pred }}=\mathrm{Chl}_{\text {meas }}$.

productive waters worldwide. Availability of MERIS data is another advantage in using remote sensing technology as a cost effective monitoring and management tool in coastal and inland waters.

\section{CONCLUSION}

The results present a case for using the NIR-Red algorithms as tools for estimating chl- $a$ concentration in the Hudson/ Raritan Estuary without the need for reparameterization of the algorithms. This will be a great asset in the real-time remote monitoring chlorophyll-a concentrations in this region. The spectral locations and resolutions of the NIR and Red channels of MERIS proved adequate to capture the spectral variations in reflectance of optically complex turbid productive waters in a wide range of chl- $a$ concentrations. Two-band and three-band NIR-Red algorithms have proven highly reliable for estimating chl- $a$ concentration in turbid productive waters [14, 16]. They have yielded consistently accurate estimates of chl- $a$ concentration when applied to MERIS data in different geographic locations including the Azov Sea and the Taganrog Bay, field spectrometer data from the Chesapeake Bay, Lake Kinneret [31], and several lakes in Nebraska [30], complimented with a large dataset of synthetically generated reflectance data [18], without the need for reparameterization. These results significantly promote the use of these MERIS-based 2-band and 3-band NIR-Red algorithms as potentially universal tools in estimating chl- $a$ concentration in coastal and inland waters worldwide.

\section{CONFLICT OF INTEREST}

The authors confirm that this article content has no conflicts of interest.

\section{ACKNOWLEDGEMENT}

This project is funded by the National Science Foundation (Grant \# BES 9806982). Support of the NASA/ Headquarters-Biology and Geochemistry Program and the AVIRIS Experiment Team are greatly appreciated.

\section{REFERENCES}

[1] Morel A, Prieur L. Analysis of variations in ocean color. Limnol Oceanogr 1997; 22: 709-22.
[2] Gitelson, A. The peak near $700 \mathrm{~nm}$ on radiance spectra of algae and water: relationships of its magnitude and position with chlorophyll concentration. Int J Remote Sens 1992; 13: 3367-73.

[3] Gons HJ. Optical Teledetection of chlorophyll a in Turbid Inland Waters, Environ Sci Tech 1999; 33: 1127-32

[4] Carder K, Cannizaro J, Chen FR, Bailey SW, Werdell PJ. Toward a climate-quality Chlorophyll_a dataset-global validation of a semianalytical Chlorophyll_a Algorithm: Proceedings of Ocean Optics XVII, Fremantlle Australia October 28,2004

[5] Darecki M, Stramski D. An evaluation of MODIS and SeaWiFS bio-optical algorithms in the Baltic Sea. Remote Sens Environ 2004; 89: 326-50.

[6] Dall'Olmo G, Gitelson AA. Effect of bio-optical parameter variability on the remote estimation of chlorophyll-a concentration in turbid productive waters: experimental results. Appl Optics 2005; 44: 412-22.

[7] Stumpf R-P, Tyler M-A. Satellite detection of bloom and pigment distribution in estuaries. Remote Sens Environ 1998; 24: 385-404.

[8] Gitelson A, Kondratyev. Optical models of water bodies. Int J Remote Sens 1991; IZ: 373-85

[9] Dekker AG. Detection of optical water quality parameters for eutrophic waters by high resolution remote sensing, PhD-Thesis; Vrije Universiteit, The Netherlands, 1993.

[10] Han L, Rundquist D-C. Comparison of NIR/RED ratio and first derivative of reflectance in estimating algal-chlorophyll concentration: A case study in a turbid reservoir. Remote Sens Environ 1997; 62: 253-61

[11] Gower JFR, Doerffer R, Borstad G-A. Interpretation of the $685 \mathrm{~nm}$ peak in water-leaving radiance spectra in terms of fluorescence, absorption and scattering, and its observation by MERIS. Int $\mathrm{J}$ Remote Sens 1999; 20: 1771-86.

[12] Ruddick KG, Gons HJ, Rijkeboer M, Tilstone G. Optical remote sensing of chlorophyll a in case 2 waters by use of an adaptive twoband algorithm with optimal error properties. Appl Opt 2001; 40: $3575-85$.

[13] Le C, Li Y, Zha Y, Sun D, Huang C, Lu H. A four-band semianalytical model for estimating chlorophyll a in highly turbid lakes: the case of Taihu Lake, China. Remote Sens Environ 2009; $113: 1175-82$

[14] Moses W-J, Gitelson A-A, Berdnikov S, Povazhnyy V. Satellite estimation of chlorophyll-a concentration using the red and NIR Bands of MERIS -The Azov Sea case study. IEEE Geosci Remote Sens Lett 2009; 6: 845-9.

[15] Yang,W, Matsushita B, Chen J, Fukushima T, Ma R. An enhanced three- band index for estimating chlorophyll-a in turbid case-II waters: Case studies of Lake Kasumigaura, Japan and Lake Dianchi, China. IEEE Geosci Remote Sens Lett 2010; 7: 655-9.

[16] Gitelson AA, Gurlin D, Moses W, Yacobi Y. Remote estimation of chlorophyll-a concentration in inland, estuarine and coastal waters. In: Q. Weng, Ed. Advances in environmental remote sensing: sensors models and applications Boca Raton: CRC Press Taylor and Francis Group 2011; pp. 449-78.

[17] Moses WJ, Gitelson AA, Berdnikov S, Povazhnyy V. Satellite estimation of chlorophyll-a concentration using the red and NIR 
bands of MERIS-The Azov Sea case study. IEEE Geosci Remote Sens Lett 2009; 6: 845-9.

[18] Gilerson A, Gitelson A-A, Zhou J, et al. Algorithms for remote estimation of chlorophyll-a in coastal and inland waters using red and near infrared bands. Opt Express 2010; 18: 24109-25.

[19] Oey L-Y, Mellor GL, Hires RI. A three-dimensional simulation of the Hudson/Raritan Estuary. Part I and II. J Geophys Oceanogr 1985, 15: 1676-709.

[20] Bagheri S, Rijkeboer M, Pasterkamp R, Dekker A. Intercalibration of the Field Spectroradiometer to Validate High Resolution Remote Sensing Data. $9^{\text {th }}$ NASA/JPL Airborne Geoscience Workshop, 2325 February 2000, Pasadena, CA.

[21] Bagheri S, Peters S, Yu T. Retrieval of water Quality Constituents Concentrations from AVIRIS data in Hudson/Raritan Estuary. Int $\mathbf{J}$ Remote Sens 2005; 26: 4013-27.

[22] Rijkeboer M, Dekker AG, Gons HJ. Subsurface irradiance reflectance spectra of inland waters differing in morphometry and hydrology. Aquat Ecol 1998; 31:313-23.

[23] NEN 6520, Water: Spectrophotometric determination of chlorophyll a content, Nederlands Normalisatieinstituut. Delft: The Netherlands 1981.
[24] Strickland JDH, Parson TR. A Practical Handbook of Seawater Analysis. Ottawa: Fisheries Research Board of Canada 1972.

[25] NEN 6484. Water: Determination of the content of not dissolved material and its ignition residue, Nederlands Normalisatie-instituut. Delft: The Netherlands 1982.

[26] Jerlov AD. Marine Optics. Elsevier: The Netherlands 1976.

[27] Mobley CD. A numerical model for the computation of radiance distributions in natural waters with wind-roughened surfaces. Limnol Oceanogr 1989; 34: 1473-83.

[28] Mobley CD. Light and water: radiative transfer in natural waters. USA: Academic Press 1994.

[29] Mobley CD , Sundman L. Hydrolight 5.0 Users' guide. Bellevue WA: Sequoia Scientific Inc: 2008.

[30] Gurlin D, Gitelson AA, Moses WJ. Remote estimation of chl-a concentration in turbid productive waters- Return to a simple twoband NIR-red model. Remote Sens Environ 2011;115: 3479-90.

[31] Yacobi Y Z, Moses W J, Kaganovsky S, Sulimani B, Leavitt BC, Gitelson AA. NIR-red reflectance-based algorithms for chlorophyll-a estimation in mesotrophic inland and coastal waters: Lake Kinneret case study. Water Res 2011: 45: 2428-36.

(C) Bagheri et al.; Licensee Bentham Open.

This is an open access article licensed under the terms of the Creative Commons Attribution Non-Commercial License (http://creativecommons.org/licenses/by-nc/3.0/) which permits unrestricted, non-commercial use, distribution and reproduction in any medium, provided the work is properly cited. 